\title{
COVID-19 and the pursuit of supply chain resilience: reactions and "lessons learned" from logistics service providers (LSPs)
}

\author{
David M. Herold \\ Institute for Transport and Logistics Management, Vienna University of Economics and Business, Vienna, Austria, and \\ Department of Business Strategy and Innovation, Griffith University, Brisbane, Australia \\ Katarzyna Nowicka and Aneta Pluta-Zaremba \\ Department of Logistics, Warsaw School of Economics, Warsaw, Poland, and \\ Sebastian Kummer \\ Department of Logistics, Jilin University, Changchun, China
}

\begin{abstract}
Purpose - The purpose of this paper is to provide new insights into the reactions and lessons learned with regard to the COVID-19 pandemic in terms of how logistics service providers (LSPs) managed to maintain supply chains resilience and what focus areas have been changed to keep operations functional and uphold financial stability.

Design/methodology/approach - Based on data-gathering techniques in interpretive research this study collected primary data via semistructured interviews, interviewing informants from selected LSPs that operate on a global scale.

Findings - The results show that LSPs have built their reactions and actions to the COVID-19 outbreak around five main themes: "create revenue streams," "enhance operational transport flexibility," "enforce digitalization and data management," "optimize logistics infrastructure" and "optimize personnel capacity." These pillars build the foundation to LSP resilience that enables supply chains to stay resilient during an external shock of high impact and low probability.

Originality/value - The results of this study provide insights into how LSPs have managed the downsides and found innovative ways to overcome operational and financial challenges during the COVID-19 outbreak. As one of the first studies that specially focuses on the role of LSPs during the COVID-19 pandemic, this study categorizes the LSPs' reactions and provides a "lessons learned" framework from a managerial perspective. From a theoretical perspective, this paper discusses the strategic role of LSPs in supply chain management and thereby extends current supply chain literature with a focus on LSP resilience.
\end{abstract}

Keywords Resilience, Logistics management, Supply chain vulnerability, Logistics service provider, COVID-19, Supply chain resilience, Supply chain management

Paper type Research paper

\section{Introduction}

This has been the most difficult shipping environment for supply chain and logistics professionals in our observed history (Jaap Bruining, Head of Europe, Coyote Logistics on 31 July 2020).

The COVID-19 outbreak in the beginning of 2020 caused an unparalleled disruption of supply chains, clearly showing the vulnerability of the globalized economy which is characterized by complex and intertwined product and material flows (Ivanov and Dolgui, 2020b; Queiroz et al., 2020; Singh et al., 2020). As a supply chain can be understood as a network of organizations mutually and co-operatively working to manage the flow of materials and information from suppliers to end users (Lambert, 2008; Christopher, 2011; Lee, 2002), it should be

The current issue and full text archive of this journal is available on Emerald Insight at: https://www.emerald.com/insight/1359-8546.htm

Supply Chain Management: An International Journal 26/6 (2021) 702-714

Emerald Publishing Limited [ISSN 1359-8546] [DOI 10.1108/SCM-09-2020-0439] stressed that global supply chains and the associated complex material flows predominately rely on logistics infrastructure (mainly transport and warehouse services) provided by logistics service providers (LSPs). LSPs play and have played a crucial role in the past decades, as companies increasingly focus on their core competencies and have outsourced their logistics functions for transport and warehousing efficiency, flexibility and capacity purposes (Gkanatsas and Krikke, 2020; König

\footnotetext{
(C) David M. Herold, Katarzyna Nowicka and Aneta Pluta-Zaremba and Sebastian Kummer. Published by Emerald Publishing Limited. This article is published under the Creative Commons Attribution (CC BY 4.0) licence. Anyone may reproduce, distribute, translate and create derivative works of this article (for both commercial and non-commercial purposes), subject to full attribution to the original publication and authors. The full terms of this licence may be seen at http://creativecommons.org/licences/ by/4.0/legalcode

Received 3 September 2020

Revised 28 December 2020

8 March 2021

23 March 2021

29 March 2021

Accepted 1 April 2021
} 
and Spinler, 2016; Lam and Dai, 2015; Liu and Lee, 2018; Wilson, 2020). A 2019 LSP study (Infosys, 2019) revealed that $53 \%$ of shippers' transportation and $34 \%$ of warehousing operations expenditure is related to logistics outsourcing, with supply chain consultancy Gartner (2019) expecting further budget increases for logistics outsourcing in the upcoming years. More importantly, by coordination and managing material flows, LSPs also have a significant impact on supply chain resilience by limiting or even eliminating risks that may occur owing to volatile demand, supply or in emergency situations (König and Spinler, 2016).

During the beginning of the COVID-19 pandemic, however, LSPs were heavily impacted by the disruptions of global chains as material production and flows stopped, declined drastically or were delayed (Choi, 2020; Ivanov, 2020b; Ivanov and Dolgui, 2020b; Paul and Chowdhury, 2020; Queiroz et al., 2020). The implications caused by the outbreak led to uncertainties for LSPs on several levels, including an unprecedented volatility with regard to logistics infrastructure demand and supply and thus to operational and personnel capacity requirements. Moreover, in conjunction with the decline and the shortages in transport during the beginning of the pandemic, LSPs immediately felt the financial impact and had to make quick operational changes to survive (Paris, 2020; Wackett, 2020; Wilson, 2020).

Given the critical role of LSPs in supply chain management, however, there seems to be only limited research so far that specifically investigates how LSPs built resilience within supply chains and reacted to the unprecedented disruption caused by COVID-19. In other words, there is a lack of understanding to what extend LSPs have reacted to the disruptions and what specific measures have been taken to ensure operational functioning and survival of the company and therefore the whole supply chain. In the paper, we argue that supply chains were able to continue to function owing to the actions undertaken by LSPs that contributed to the supply chain resilience. In particular, we ask the following research questions:

RQ1. What were the implications of the COVID-19 pandemic on the LSPs' business and operations to maintain or improve supply chain resilience?

RQ2. How did LSPs react to the COVID-19 outbreak and what has been learned from these reactions to preserve supply chain resilience now and in the future?

In this paper, having interviewed LSPs with a global footprint, we attempt to provide insights into the reactions and lessons learned with regard to the COVID-19 pandemic. So far, only limited insights exist about how LSPs managed to maintain supply chains resilience and what focus areas have been changed to keep operations flowing and uphold financial stability. By providing insights into this topic, the contribution of this paper is fourfold: First, as far as the authors are aware, this study is the first study that specifically investigates the implications of COVID-19 from a LSP perspective. So far, existing literature researching the supply chain survivability (Sharma et al., 2020) or supply chain resilience (Pettit et al., 2019; Pettit et al., 2010; Ponomarov and Holcomb, 2009), even during the COVID-19 (Golan et al., 2020; Ivanov, 2020b;
Ivanov and Dolgui, 2020b; Remko, 2020), has not specifically investigated or even neglected the role of LSP in a pandemic or crisis situation. Second, the paper presents and discusses the immediate actions of the mainly operational decisions taken by LSPs, thereby providing an overview about the real-world reactions of LSPs and their impact on supply chain resilience. Third, our study provides insight into how LSPs have managed the downsides of the pandemic as well as have found innovative ways to overcome operational and financial challenges, thereby not only allowing us to categorize the LSPs' reactions, but also provide an overview about the "lessons learned" from a managerial perspective. Fourth, by recalibrating the concept of supply chain resilience to LSP resilience, we extend current LSP and supply chain literature with a concept that is better suited to describe the immediate reactions and actions during an external shock of high impact and low probability.

The remainder of this paper is structured as follows: In Section 2, we define our LSP resilience framework that we will be using to categorize the reactions of the LSPs. This is followed by the description of the methodology and the subsequent data collection and analysis. In Section 4, we present our results according to the identified themes from the data analysis and introduce a lessons-learned-cycle that consolidates the findings from the interviews. We conclude by summarizing the key findings and highlighting the limitations of the study with recommendations for future research.

\section{Logistics service providers resilience}

LSPs play an important role in the resilience of supply chains through their integration and collaboration of logistics activities along global supply chains (Panayides and So, 2005). With companies focusing more on their core competencies, the outsourcing to LSPs gives shippers exactly the carrier capacity they need and provides flexibility in the supply chain (Wilson, 2020). The on-demand capacity, flexibility and innovations (Grawe, 2009) put LSPs in a strategically crucial position for a company's daily operations and should also help companies to mitigate negative effects arising from an emergency situation such as a supply chain disruption (Gkanatsas and Krikke, 2020; Lam and Dai, 2015; Liu and Lee, 2018). In former crises such as the Icelandic volcano eruption, for example, the LSP DHL were able to reroute flights to Southern Europe and immediately shifted shipments onto trucks and trains to minimize their customers' losses (König and Spinler, 2016). As such, LSPs can be regarded as a crucial part of supply chain resilience as their assets and the associated logistics infrastructure (mainly transport) provides them with a potential strategic advantage to fulfill the customer demands (Christopher, 2011). However, the unprecedented and unique scenario of the COVID-19 pandemic and its disruption of global supply chains clearly showed that LSPs were overwhelmed: LSPs, relying on global material flows, were suddenly confronted with shortages and delays of critical items, causing a ripple effect within operations and leading to a decline in productivity, revenues and profits (Choi, 2020; Ivanov, 2020b; Ivanov and Dolgui, 2020b; Paul and Chowdhury, 2020; Queiroz et al., 2020).

In Austria, for example, LSPs were hit in March 2020 by a unprecedented drop in Austrian industry production of $38 \%$ 
compared to March 2019 (Mayerhofer et al., 2020), leading to decrease in cross-border transport capacity of Austrian companies and LSPs by $18 \%$ in second quarter in 2020 compared to 2019 (Statistik Austria, 2020). Also in March 2020, 63\% of Austrian companies observed delays and disturbances along their global supply chains, with $11 \%$ reporting a complete disruption of their supply chains (BMOE, 2020). Worldwide, studies show that the outbreak caused an approximately 6 million twenty-foot equivalent units (TEU) volume drop in Quarter 1 2020, questioning the resilience capability and the financial stability of some LSPs (Paris, 2020; Wackett, 2020).

As such, the unprecedented and immense impact of the pandemic threatened the survivability of LSPs and thus the associated survivability of global supply chains (Sharma et al., 2020). As a response to the survivability concerns of supply chains, academia and practice called for research on increasing the supply chain resilience on a global and on a local scale (König and Spinler, 2016; Pettit et al., 2010). Supply chain resilience literature has increased in the last decade and is becoming a mainstream topic among academics (Hosseini et al., 2019; Pereira et al., 2014; Pettit et al., 2019; Ponomarov and Holcomb, 2009; Scholten et al., 2014; Tukamuhabwa et al., 2015). Supply chain resilience is also the most popular theme to investigate the implications of COVID-19 from a logistics and supply chain perspective (Choi, 2020; Golan et al., 2020; Ivanov, 2020a; Ivanov and Das, 2020; Ivanov and Dolgui, 2020b; Paul and Chowdhury, 2020; Queiroz et al., 2020; Remko, 2020; Singh et al., 2020).

Surprisingly however, only limited research exists that investigates specifically how LSPs can help to maintain or build resilience in and for supply chains, in particular regarding the COVID-19 pandemic. Only recently, scholars have looked at vulnerability in logistics outsourcing (König and Spinler, 2016), security design of LSPs (Lam and Dai, 2015) or integration and resilience of and through LSPs (Liu and Lee, 2018). In other words, it is still not clear to what extent LSPs have reacted to the disruptions during COVID-19 and what specific measures have been taken to ensure operational functioning and survival - for them and for global supply chains. Moreover, to understand these reactions, we argue that drawing purely on supply chain resilience literature will provide an incomplete answer. That is, because although different definitions of supply chain resilience exist (Christopher and Peck, 2004; Kim et al., 2015; Ponis and Koronis, 2012; Ponomarov and Holcomb, 2009), these concepts of supply chain resilience focus mainly on strategic planning which aims to determine the required operational flexibility for the supply chain network (Pettit et al., 2019; Pettit et al., 2010; Ponomarov and Holcomb, 2009).

These definitions highlight the capability of the supply chain to adapt to unforeseen events, respond to disruptions and recover from them by maintaining continuity of operations (Gölgeci and Ponomarov, 2015; Ponomarov and Holcomb, 2009). A resilient supply chain can thus adapt to unpredictable events and return to its original state (Coutu, 2002) or transform to another configuration (Christopher and Peck, 2004). It may also be beneficial for the supply chain not to return to its original "shape" following a disruption or change impact, but rather to learn from the disturbance and adapt into a new configuration (Pettit et al., 2010). In accordance with these two approaches, the resilient supply chain has on the one hand the ability of simple and reactive adaptation (a single or double loop learning, respectively), enabling easy correction of disturbances or a preventive response to unexpected changes, but on the other hand the ability to dynamically react by means of pre-adaptation to undefine changes (i.e. learning in a triple loop) (Swierczek, 2019).

The COVID-19 pandemic clearly showed that the resilience planning of global supply chains seems to have worked only partly: in some supply chains demand increased dramatically and supply was not able to cope with the demand (such as hand sanitizer, facial masks, disinfection spray) or demand dropped dramatically leading to production stops, bankruptcies and government intervention (Lund et al., 2020). As a consequence, we argue that supply chain resilience depends on the resilience of LSPs. In other words, the main rationale behind our argument is that supply chain resilience has been and can be built by the greater involvement of resilient LSPs. The COVID-19 pandemic demonstrated that the strategic function of LSPs in the supply chain affects not only the supply chain performance per se but may also represent a competitive advantage in emergency situations (König and Spinler, 2016; Lam and Dai, 2015; Liu and Lee, 2018; Wilson, 2020). In other words, the COVID-19 situation stressed the need for flexible reconfiguration of logistics infrastructure and its resources to maintain flows and consequently to keep supply chains "moving." This puts LSPs in a crucial position as they not only possess the operations know-how but also have access to multiple ad hoc logistics resources and are able to quickly implement innovative solutions in complex supply chain environments.

Subsequently, for the supply chain and its logistics activities to function properly, LSP need also to be resilient, i.e. their operational and their financial capabilities have to be protected. In the context of our research, LSP resilience focuses on actions taken by the LSP to survive in the short term and with an emphasis on the LSP financial stability to have the operational and financial strength to contribute to the overall supply chain resilience. In particular, we argue that the LSP resilience concept has two key characteristics: First, LSP resilience comprises the innovative character to respond to the pandemic through innovative ideas to create business opportunities. For LSPs, the recovery phase opened up opportunities to create incremental logistics infrastructure - mainly transport capacity - and realize potential additional revenue streams (ICAO, 2020; Wilson, 2020), thus LSPs found ways to leverage the upsides. More specifically, this point emphasizes the innovative character and the transformation of the focus from pure efficiency to resilience by integrating the financial part as a core aspect. Financial stability and additional revenue streams have rarely been mentioned in supply chain resilience literature and seem to have been neglected so far. This is somewhat surprising, given the financial problems, potential bankruptcies and the LSP survivability concerns caused by the pandemic.

Second, LSP resilience comprises measures that need to be taken to manage the downsides during a disruption. It seems that especially during the beginning of the pandemic, companies were not mainly relying on their strategic resilience measures, but rather responded quickly or ad hoc on an operational level. 
These adjustments can be related to the concept of adaptive management within supply chain resilience (Li et al., 2010; Pathak et al., 2009; Ponomarov and Holcomb, 2009). More specifically, the goal of adaptive management is "to make supply chain responsive [...], cost-effective, and competitive in order to increase customer satisfaction and decrease costs, resulting in increasing supply chain profitability" (Ivanov et al., 2010, p. 411). The focus here clearly lies on optimizing operational and logistics resources and personnel. In the context of COVID-19 disruptions and the related shortages and production stops, adaptive management would require downsizing operations and minimize losses, i.e. managing the downsides and its implications on the organization caused by the pandemic.

As a consequence, we argue that LSPs during the pandemic did not only survive because they relied on their pure operational resilience measures, but rather because they took a more holistic view of LSP resilience, which we define as "The LSPs' capability during an external shock of high-impact and low-probability, to adapt, reallocate and introduce operational measures to protect their core operational capacity as well as to create business opportunities to return to its original or improved financial profitability to contribute to the resilience of the supply chain."

These two LSP resilience key characteristics will be subsequently used to examine the reactions of LSPs. In the following section, we explain the research design and how we collected and analyzed the data from selected LSPs with a global footprint.

\section{Methodology}

\subsection{Research approach}

The overall research aim is to categorize and understand the reactions of the LSPs during the pandemic for the survival as well as what actions have been taken to secure LSP resilience. To classify the reactions and actions, we adopt the interpretive research approach from Darby et al. (2019). The interpretive approach allows us to generate meaning and expand boundaries, more as a process rather than with an explanation of an end product achieved by showing associations of variables (Denzin, 1984; Hudson and Ozanne, 1988). As such, the interpretive approach studies a particular phenomenon in a particular place and therefore "particular motives, meanings, and experiences are studied to provide 'thick descriptions' that are time-and context-bound" (Darby et al., 2019, p. 398). The research process in this paper follows the interpretive research approach using a part-to-whole process, represented by a hermeneutic cycle (Darby et al., 2019). The beginning of the cycle presents the orienting frame-of-references that explains the self-relevance of the context (Thompson, 1997). In this paper, the orienting frame-of-reference are the following two LSP resilience characteristics:

1 leverage the upsides, i.e. how innovation helped LSPs to survive operationally and financially; and

2 manage the downsides, i.e. how LSPs managed the negative implications of COVID-19 on their operations and business.
These two reference points are used to categorize the downsides and upsides and the associated actions and reactions.

\subsection{Selection of context and sample}

Unlike the positivist approach, which aims to generalize the findings, the context selection within the interpretive approach is driven by understanding rather than generalizing (Darby et al., 2019; Denzin, 1984). Owing to the emphasis of an in-depth understanding of the context, the selected amount of informant cases in interpretive research approaches is always small, varying between 3 and 20 (Darby et al., 2019; Fournier, 1998; Thompson et al., 1989). Therefore, based on the orienting frame-of-references, the context in this paper are the LSPs. Since the interpretive approach follows a judgment sample strategy, i.e. that the samples are based on the opinion of the expert (Deming, 1990), we selected four LSPs operating in Austria based on the following criteria: First, the LSPs need to have a global presence (i.e. are operating in an international/global market) and thus rely on global supply chains. Second, the LSPs have to provide all modes of transport (land, rail, sea, air), so similarities and differences between transport modes can be revealed. Third, it was decided to focus on two major LSPs as well as on two small and medium LSPs to get a better understanding how firm size influences (re)actions to the pandemic. Although Austria's LSP competition consists of multiple small LSPs and all major European and international LSPs, we were confident that these four LSPs represent an adequate cross section of the LSPs in Austria.

For the interviews, four informants, each representing one of the four LSPs, were purposefully selected (Yin, 2014) to ensure that the respondents possessed an in-depth understanding and rich experience of the operational impacts and their underlying processes from a LSP viewpoint. The informants consisted of senior operations managers and global sales executives with an international track record in logistics and supply chain as well as strategic and operational management experience. As the aim of the interpretive research is to get in-depth knowledge and the information has been received with a promise of confidentiality, we guaranteed anonymity to the informants. General information about the companies are described in Table 1 below.

\subsection{Data collection}

Based on data-gathering techniques in interpretive research we collected primary data via semi-structured interviews, interviewing informants from the selected companies described above. Semi-structured interviews were chosen as they ensure that the content of the interview is focused "on the issues that are central to the research question, but the type of questioning and discussion allow for greater flexibility than does the survey interview" (Minichiello et al., 1995, p. 65). Although we used the orienting frame-of-reference as a guide, our questions were not "strictly scripted" (Yin, 2014, p. 134) and we followed a conversational mode to encourage a two-way interaction to better understand the particular actions and reactions and their implications of the LSPs during the COVID-19 pandemic. As such, the questions focused specifically on the COVId-19 
impact and comprised four main issues: a) operational performance, b) sales activity, c) personnel capacity and d) upper management decisions.

The interview questions were short and open-ended with the goal to create a circular dialogue influenced by the recurring interaction between interviewee and researcher (Wimpenny and Gass, 2000) to understand the informants "on their own terms and how they make meaning of their own lives, experiences, and cognitive processes" (Brenner, 2006, p. 357). To keep the conversation going, we made use of probes and follow-up questions not only to stimulate the informant to expand upon original comments (Yin, 2014), but also "to hear the meaning of what is being said" (Rubin and Rubin, 2011, p. 7). The interviews were conducted either face-to-face, or via Zoom and all interviews were recorded and transcribed in August 2020.

To expand the information from the interviews we collected data based on secondary data sources. According to Rabinovich and Cheon (2011), the use of secondary data has some unique advantages like less subject to biases, higher internal validity and availability in great quantity, that are valuable to gain deep insights into logistics phenomena. Therefore, we used internal (e.g. documentations, digital records, archival records) and external data sources (articles, reports of agencies, industry reports) of the companies (Parikh, 2002) to gain further knowledge about the implications of the COVID-19 pandemic and the (re)actions of the LSPs. We used the most up-to-date data to guarantee the focus on the implications caused by the COVID-19 pandemic during the beginning in 2020 .

\subsection{Data analysis}

In the data analysis stage, we first analyzed each case intratextual (Darby et al., 2019) using the orienting frame-ofreferences (i.e. the two LSP resilience key characteristics (a) leverage the upsides, and (b) manage the downsides) for interpretation. By reading and rereading the transcripts individually, we interpreted the text in context for each of the LSPs (Darby et al., 2019; Murray, 2002; Thompson, 1997). This intratextual analysis was concluded by a detailed summary including a list of the major findings for every LSPs to identify the reoccurring and main themes. This analysis stage aimed to provide all information in contextual detail (Prasad, 2017) and produce "thick" descriptions (Geertz, 1973). After that, we analyzed the LSPs intertextual (Darby et al., 2019), meaning across each other to identify common themes. In this step, we searched for shared storylines concerning the reactions and actions for the purpose of achieving a higher level of abstraction (Prasad, 2017). In other words, we performed a thematic analysis and coded the material to identify commonalities or intertextual patterns. This step allowed us to prepare a list of the actions and reactions by the LSPs during the COVID-19 pandemic and to identify overarching themes. Following the approach from Arnould and Wallendorf (1994) we repeated the process of thematic analysis until the orienting frame-of-references, i.e. the reactions and actions, were contextualized.

\section{Reactions of logistics service providers to COVID-19 outbreak}

The analysis of the interviews revealed the following five main themes under which the reactions and actions can be categorized, leading to a LSPs resilience framework based on the two LSP resilience key characteristics (Figure 1):

- create revenue streams;

- enhance operational flexibility (mainly transport and warehousing);

- enforce digitalization and data management;

- optimize logistics infrastructure capacity; and

- optimize personnel capacity.

While the first two themes are linked to leveraging the upsides, the last two themes can be attributed to the managing the downsides. The theme "enforce digitalization and data management" has been mentioned as (re)action in the downsides and the upsides, thus it comprises both sides. The re (actions) of LSPs are presented in Section 4.1 according to the identified themes.

\subsection{Leveraging the upsides: create revenue streams}

For LSPs, the interviews and the secondary data showed that the disruption of global supply chains provided an opportunity to create additional revenue streams owing to overall lack of transport capacity, in particular in the air cargo sector. More specifically, in April 2020, "all trade lanes across the world seeing double-digit air cargo capacity decline compared to last year [...] with transatlantic air cargo capacity down $44 \%$ from the US into Europe, and 58\% in the reverse direction" (Wilson, 2020, p. 78) the disruption led to drastic reduction of aircraft belly cargo capacity, which accounts for approximately half of all air cargo (ICAO, 2020).

As a consequence of this "bottleneck," air freight rates surged up to six times higher than normal, and LSPs were in the unique position to take advantage of their transportation network and offer clients transport capacity through their own or chartered planes. In particular, the major freight integrators such as FedEx, DHL or UPS, having significant capacity, were able compensate the lack of aircraft belly capacity, as C4 confirmed: "With China returning to the 'new normal' and starting to produce again, we saw an enormous uptake in demand on our Asian routes." This demand led to additional revenues streams and "cushioned" the impact from the pandemic for LSPs, with C3 saying "The Asia business saved us [financially]." One major factor was the pursuit of national

Figure 1 LSP resilience framework - (Re)actions of LSPs to the COVID19 pandemic

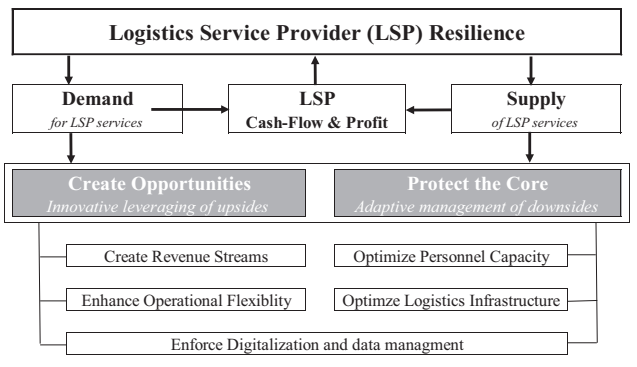


governments to secure PPE, leading to "record yields" with spot rates out of China reaching US $\$ 18$ per kilo and prices of a 747 charter selling for US $\$ 1.5 \mathrm{~m}$ by the end of April (Putzger, 2020).

However, sales was not always prepared to deal with these changes: "I suddenly was confronted with requests for airfreight rates and charter deals, a business I was not really familiar with" (C2) and "My focus switched from my usual customer requests and transport demands to this spontaneous, large one-off shipments for PPE" (C1). Nevertheless, the interviewees all suggest that the redirection to more immediate, pandemic-related business not fully compensated the drop in "business-as-usual" volumes, but significantly helped the LSPs to generate much needed revenue. A glance at the results of global freight integrators and LSPs indicates that COVID-19 had an impact on revenues and profits, but no loss was reported. For example, UPS stated in their second quarter earnings on July 30, 2020, "Our results were better than we expected, driven in part by the changes in demand that emerged from the pandemic, including [...] COVID-19 related healthcare shipments and strong outbound demand from Asia" (UPS, 2020). Similarly, DB Schenker, a leading German-Austrian logistics service provider, also announced on 30 July 2020 that "DB Schenker [...] has done well in the crisis, despite falling revenues, [and] lifted adjusted earnings before interest and taxes to EUR 278 million, an increase of $16.8 \%$ year on year" (DB Schenker, 2020).

These reactions indicate a "lesson learned" that can improve the LSP resilience. It seems that John Adam's quote "every problem is an opportunity in disguise" is also true for LSPs during a pandemic. Our interview data suggests that after an initial shock stemming from the drastic drop in volumes owing to the supply chains disruptions, the strategic transport assets and the associated transport capacity played a significant role to quickly generate revenue through "new" transport requests regarding pandemic related shipments such as healthcare shipments and PPE equipment. This immediate availability of transport assets and capacity and its sales significantly mitigated the loss of revenue during the beginning of the COVID-19 outbreak. However, our interview data also suggests that not all sales, admin and operations workers were fully prepared to deal with the different transport requests, thus contingency training or contingency manuals may help to further drive business and to bet a better understanding what about the opportunities related to a crisis.

\subsection{Leveraging the upsides: enhance operational flexibility}

The disruption of global supply chains challenged the LSP sector with its very volatile transport demands (Paul and Chowdhury, 2020; Queiroz et al., 2020). In the beginning of the pandemic when global production halted and fleets and trucks were grounded, LSPs had to cut transport capacity drastically. During the recovery phase, LSPs had to deal with a combination of lack of aircraft belly capacity and urgent requests for PPE equipment, reversing the situation as clients, governments and other critical parties asking for transport capacity which was not available on the market (Lund et al., 2020).
One interviewee stated: "It was crazy, in the beginning, we were thinking we will all lose our jobs because there is nothing to transport to, but then suddenly business increased dramatically and we couldn't handle all the requests. We knew we need to look for solutions for our customers" (C1). As a consequence of the lack of capacity, by mid- to end of April, several passenger airlines established regular cargo flights. For example, Virgin Atlantic provided a 787-passenger aircraft exclusively for the UK Department of Health and Social Care flying three times a week between London and Shanghai for PPE and health supplies for hospital staff. Going even further, Air Canada was the first passenger airline that decided to remove seats to handle the increase in cargo shipping requests (Horton, 2020). However, LSPs also used passenger airlines to increase their transport capacity. For example, DB Schenker removed the seats from three Iceland Air $767 \mathrm{~s}$ for regular cargo shipments from Asia to Europe and the USA (DVZ, 2020).

As a consequence of this "unprecedented scenario" (C2), LSPs needed to quickly adapt to this new environment, thus challenging an existing system and incorporating more transport flexibility in the shipping network. On an immediate operational level, our interviews reveal that the change worked well, with C2 stating: "I was quite surprised how quick management decided to create new capacity. I guess they saw the money-making opportunity, but it was also about establishing themselves as a reliable partner in the time of crisis." C3 stated that "In sales, we changed the indirect reporting lines that means, as our 'normal' product demand dropped, we communicated directly with our charter division and we added personnel to handle the requests."

From a strategic perspective, the LSPs seemed to have examined the current and future network needs and set up calls with their main partners/service providers. From a network perspective, C3 said "It was sometimes really hard to get an overview about today's network, the changes are really drastic and the usual providers and shippers may no longer be valid," leading to network uncertainty with regard to reliability of shippers. As a consequence, management set up strategic calls with the main shippers: "We made a list, even with the shippers that are not currently shipping with us, to talk to them and get a realistic idea about their capacity, problems and also what the plan for the rest of the year" (C4).

These findings allow us to draw three conclusions how LSPs can increase their LSP resilience through transport flexibility. First, the deal needs to be closed: the interviewees indicate that sales alignment is key, i.e. it maybe that sales people with different products get requests for a product that they not originally have in their portfolio, however, it is important that this request can be handled. As a consequence, setting up new direct and indirect lines helps to secure business. Second, the deal needs to be handled: because of the lasting change in product demand, e.g. a change from B2B express shipments to air cargo belly freight, operational resources need to be reallocated to respond to these demands, i.e. trained personnel should be added quickly and if required, organizational changes should be made. Third, the deal needs to be transported: to have transport capacity available, management need to examine the network needs and subsequently talk to their strategic partners and providers to forecast the volumes and demands. 


\subsection{Enforce digitalization and data management}

The interviews revealed that the pandemic was a major driver behind IT solutions and a main driver for digitalization, i.e. for LSPs to find ways to digitize certain processes to maintain business critical functions. Studies show that LSP operations, in particular in sea-, rail- and airfreight, are still characterized by limited innovation capabilities and a low level of digitalization (Busse and Wallenburg, 2011; The Economist, 2018; Fruth and Teuteberg, 2017; Yang, 2019). As such, the circumstances and the protective measures that had to be introduced and affected operations and workforce, did not only challenge existing processes but could also be seen as an opportunity to drive digitalization in their respective organizations (Lund et al., 2020). We found that our interviewees saw digitalization as an opportunity to tackle the downsides of the disruptions as well as to push digitalization for further growth opportunities.

To react to downsides and use digitalization to implement basic protective measures to further continue operations comprised two key elements: the operations and the workforce. Overall, all interviewees have observed an acceleration of process digitalization, both for customers, employees and within the companies' operations. C4 stated: “Instead of telephone and personal meetings, customers and employees are increasingly using Zoom or other video conference tools." C4 also said that "we saw customers who were originally still expecting a handwritten POD [Proof of Delivery] moving to digital PODs and even digital invoicing."

The digitalization was also sometimes forced owing to certain restrictions as in some countries as C1 states: "When our truck driver arrives in Italy, he is not allowed to exit the truck cabin, so all his paperwork is with him in digital form". But the interviewee further commented that "although most EU countries have adopted the use of digital freight documents, some, including Germany, have not," emphasizing the fragmentation across borders in the European Union and the need for a more holistic approach.

However, all interviewees see digitalization and the associated data management also as an opportunity to better understand market unpredictability and better planning on a purely operational level. "So far, we don't have any specific tools that can help us to predict volumes in the times of disruptions or crisis. We receive our yearly volume target at the beginning of the fiscal year, but it's very static and it is too complicated to incorporate dynamic volume changes such as from COVID-19" (C4). The interviewee further states: "although we can get sufficient information about shipments, mainly from the customers' entries, our legacy system is quite old and cannot imagine how it can be digitalized." Two interviewees specifically addressed the lack of digitalization stating that "In our warehouse, we can't digitally measure the dimensions of packages and pallets, which may result in a revenue loss" (C2) and "from a strategic viewpoint, I hardly receive reliable updates from our management about the change in volumes, but when I look at, for instance, Amazon and its data management and their approach to anticipatory shipping, we need to catch up to plan better in the short-term and the long-term" (C1).

As a result, these findings allow us to conclude with two management lessons learned to improve the supply chain resilience through LSPs. First, the adoption and implementation of digitalization for the workforce and on the operational level seem to be rather tied to the unwillingness or resistance to organizational change. However, because of COVID-19, LSPs were under pressure to digitize critical processes; it seems that COVID-19 has raised awareness and has thus accelerated the digital transformation. We could observe differences between large and small companies: large companies seem to have reacted more quickly, while small companies seem to lag behind with regard to digitalization. Second, investments in digitalization for (big) data management seem not to be an "if" anymore, but increasingly a "when" question. On an operational level, LSPs seem to understand that better data management can help to further consolidate shipments and better plan last-mile deliveries. On a strategic level, the use of data and accurate tracking processes can, for example, help to adapt shipping transportation speed (e.g. slow steaming), so that the 'floating storage' arrives in warehouses when needed. Three out of four interviewees stated that digitalization is a challenge in their company and with Amazon and Alibaba, which have already filed patents for anticipatory shipping (Gunasekaran et al., 2017) to "predict when a customer will make a purchase and begins shipping the product to the nearest hub before the customer places the orders online" (Lee, 2017, p. 593), the need for digitalization is seen as a crucial investment.

\subsection{Optimize logistics infrastructure}

The main element for LSPs that has been affected by COVID19 was related to transport capacity and its drastic reduction owing to the global supply chain disruption (Ivanov and Dolgui, 2020b). Global LSPs depend on global supply chains and the disruption led to two major changes with regard to transportation. First, the abrupt decline in supply chain activity owing to COVID-19 led to uncertainty on a strategic level, as LSPs could neither predict which of their strategic customers would continue shipping, nor to what extent strategic transport partners or providers were able to provide flexibility in geographical and quantity terms. Second, the abrupt decline also led to uncertainties on an operational level, as less material and goods were shipped and or other materials than planned needed to be transported.

To handle the minimized volume, the LSPs mainly relied on usual savings and consolidation measures, which can be summarized in three points. First, trucks driving not with full capacity were consolidated, as Interviewee C1 said "The first thing we did was use only half of our trucks when the shipping volume dropped." Second, for the last-mile deliveries, the use of sub-contractors that usually transport the excess packages were cut: "We kept all our main transport lines, but made significant changes in the last-mile delivery. We did not only reduce the number of sub-contractors immensely, but also restructured our route planning in order to balance the utilization of the vehicles and drivers" (C3). Third, operations management cooperated with sales to predict the volume and to incorporate special requests, as C4 said: "The most important thing for us was to make sure that we know where volume was going to come from and to find out which big customers have been affected." The interviews suggest that the cooperation with sales not only played a crucial part for special 
pick-up and delivery requests, but also in overall transport planning process. From a warehouse perspective, C3 also stated that inventory management need to change on a strategic level, stating "[The crisis] showed clearly that inventory management is not made for a situation like this. In earlier days, an ideal warehouse operation is a 24 -hous operation with no excess inventory, but I am convinced that redundant inventory and lights-out warehousing will become the norm."

We can draw two main management "lessons learned" for the LSPs' resilience from these findings. First, to quickly react to low volumes that need to be transported, the choice of subcontractors should be approached in a more strategic way. Our interviews suggest that is not always the case as C2 stated "The drop in volumes happened quite quickly and was somehow expected, so we still had too many [delivery] vans for too less packages," thus a more strategic approach to outsource transport capacity is recommended. Second, the communication and cooperation between sales and operations was crucial to predict volumes and organize transport capacity accordingly. C3 stated "I know the sales people quite well, so I had no problems to bother them multiple times a day to find out what I need to prepare for this or the next day," thus more mandatory and frequent communication between sales and operations can help to better plan transport operations.

\subsection{Optimize personnel capacity}

The disruption of supply chains through COVID-19 had two major effects on employees in the logistics industry: First, the disruption, i.e. the stopping of global material flows dramatically reduced the workload for LSPs, thus leading to personnel overcapacities at LSPs companies mainly on an operational level. Second, employees experienced changes to the workplace, e.g. working from home was an option that was offered or ordered to minimize the spread of the virus.

To tackle overcapacities, i.e. Austrian companies could apply for the so-called "Kurzarbeit," i.e. short-time work. In simple terms, short-time work refers to a temporary reduction of working hours for employees, but the non-worked hours are subsidized by the state to bring the employee's income close to their normal wage level (Eurofound, 2020). The main advantage of short-time work is not only to safeguard jobs and know-how, but also to maintain flexibility in personnel deployment, to retain valued employees and preserve the liquidity of companies (Schnetzer et al., 2020).

Three of the four interviewed companies applied for short-time working when the crisis hit: "As soon as we knew that the German automotive manufacturers will shut down, we realized that there was no enough work" (C1). Statistics show that short-time work increased as of April drastically, leading to 1,37 million short-time workers in June (which represents more than $1 / 3$ of the entire Austrian workforce) (Hager, 2020). However, the concept of the short-time work was used only until June as LSPs saw an uptake in businesses, with interviewee C stating "We could see an uptick of airfreight coming from China and the Asia region, so business was running again." One company didn't even send their employees into short-time work, saying "Although we are a truly global company, our presence here in Austria is rather small, so kept all people in work and pretended it is business as usual" (C2). At the time this article was written, no LSP company was using short-time work anymore and all have returned or work at normal business hours.

Regarding the workplace changes, i.e. the working from home for admin/sales and office staff, also seemed to pose a challenge for management in the beginning. One interviewee stated that: "It took a while before we found the best way to work for our employees. Some have to work from home because they have children, while others are more productive at home. We had also workers who couldn't concentrate at home - so, flexibility was key here." For warehouse workers, courierand truck-drivers as well as for almost all operations employees or managers, however, working from home was not an option and management introduced protective measures at the workplace against COVID-19. We observed similar policies and procedures among the LSPs, with Interviewee C2 saying: "Safety is of utmost importance, so we developed specific measures for our drivers." The interviews suggest that management focused on four key areas: First, basic protective measures were introduced, i.e. information signs were put up for social distancing and washing hands. Second, drivers should check before driving whether enough face masks, gloves and hand sanitizer is available and to clean the inside and outside of the vehicle. Third, while driving, open the windows and always ask people to maintain distance. Fourth, the delivery should take place contactless, so communicate with the customer in advance to avoid contact.

The interviews allow us to draw three main points that management can learn from these reactions to LSP resilience. First, it's safety first, i.e. make employees feel safe by introducing protective measures, offering advice and daily updates and communication. Second, use short-time work as a measure to protect the business, the knowledge and to build loyalty among employees. Third, develop a return-to-work plan for non-operations employees while at the same time engage with HR to discuss more flexible work models in the future.

\section{Lessons learned}

The findings allow us to consolidate the information from the interviewees to derive key lessons learned from the reactions and actions from LSPs as a response to the COVID-19 pandemic. More specifically, we found that the reactions and actions to the Covid-19 outbreak can be consolidated around three pillars: (1) transport (logistics infrastructure), (2) personnel and the (3) overall organizational response.

First, transport seems to be the dominant pillar as it refers to three of the five identified themes in the findings: "create revenue streams," "enhance operational flexibility" and "optimize logistics infrastructure capacity," thereby highlighting the importance of operations resilience during a time of crisis. In particular, the interviewees revealed that cutting transport capacity saved money and help to drive down costs, but at the same transport capacity had be 'created' to fulfill immediate requests that may not fit ideally into the standard services provided by LSPs. Moreover, the crisis showed that the volatility regarding transport demand and supply should be better balanced, i.e. a more strategic approach 
with regard to sub-contractors' flexibility is recommended and that lights-out warehousing and redundant inventory may help to keep the supply chain resilient. While the first approach from LSPs to outsource transport capacity or to demand more flexibility from sub-contractors is a common approach in logistics operations (Chen et al., 2011; Svensson, 2001), the return to excess inventory and lights-out warehouses can be regarded as an fundamental change that contradicts JIT concepts and the pursuit for efficiency in inventory management in the past decades (Cachon and Fisher, 2000; Småros et al., 2003; Waller et al., 2008). The findings indicate, however, that LSP might in good position to take over the inventory management for critical supplies and thus contribute to a greater supply chain resilience.

Second, the findings also revealed that staff and personnel issues are of high importance, in particular to address the uncertainty stemming from the disruptions and to maintain productivity levels. All interviewees agreed that the option to use short-time work was an ideal option offered by the government as it provided not only security to the employees but also helped to mobilize personnel capacities as soon as the recovery phase began. The interviewees also raised that the work-from-home (WFH) option worked surprisingly well, but that workers are keen to know when they can return to the office, thus a return-to-work plan is recommended. However, the findings raise questions about the future of work for admin and office workers, as resistance to WFH and prejudices about productivity issues when working from home appear not to be confirmed (Kramer and Kramer, 2020). In particular, in times of increasing usage of digital products and services, LSPs may adopt more flexible working models to keep critical employees or to attract high potentials.

Third, from an organizational perspective, the dominating theme was to drive digitalization within the company not only for safety and more flexibility but also on operational level to receive for real-time data and more accurate forecasts for a better planning. The reflections of the interviewees regarding digitalization indicate that LSP should strive for what Stank et al. (2019) calls the "digitally dominant paradigm" and its adoption in supply chain management. Although digitalization research has only recently increased in logistics and supply chain sphere, the opportunities through big data, predictive analysis or blockchain can be regarded as game changers for the entire industry (Cichosz et al., 2020; Dobrovnik et al., 2018; Garay-Rondero et al., 2019; Herold et al., 2021; Holmström and Partanen, 2014; Hribernik et al., 2020; Ivanov and Dolgui, 2020a; Kummer et al., 2020; Mikl et al., 2020; Mikl et al., 2020; Queiroz et al., 2019; Roßmann et al., 2018; Saberi et al., 2019). It was also raised that in case of a contingency situation such as the pandemic, more emphasis should be given to the communication between operations and sales to both secure and drive business opportunities. It seemed that the alignment between operations and sales is a contemporary issue that has been addressed by scholars and in practice (Grimson and Pyke, 2007; Kaipia et al., 2017; Oliva and Watson, 2011; Rangarajan et al., 2018). However, the pandemic raised questions how operations and sales can effectively work together in the time of crisis and in particular how reporting lines should be changed to react to new business opportunities.
It needs to be emphasized that some of the lessons learned are context-specific, i.e. they can be applied to an Austrian context only, while others may be applied transnationally and for the entire LSP industry. For example, the implementation and use of short-time work is strongly related to the Austrian social system and the country-specific governmental support, while the increasing role of digitalization and a better salesoperations relationship within organizations addresses a broader management issue that is not country-specific. The lessons learned for transport and the associated logistics infrastructure can also be rather seen as an industry-specific issue rather than an Austrian issue. Overall, these lessons learned provide a snapshot of the actions and reactions taken by Austrian LSPs during the COVID-19 pandemic, and while some of these findings can only applied in an Austrian context, this paper provides insights into how LSPs managed to keep their supply chains resilient.

\section{Conclusion}

In this study, we set out to provide insights into the reactions and lessons learned from LSPs regarding the disruptions caused by the COVID-19 pandemic. To categorize the reactions, we developed a LSP resilience framework that includes categories for managing the downsides as well as leveraging the upsides during a pandemic. To understand the reactions, we used an interpretive research approach using primary data from interviews with LSPs and secondary data to showcase operational decisions and specific actions based on our LSP resilience framework.

The results show that LSPs have built their reactions and actions around five main themes: "create revenue streams," "enhance operational flexibility," "enforce digitalization and data management," "optimize logistics infrastructure capacity" and "optimize personnel capacity." The analysis revealed mainly similar actions regarding the handling transport capacity and personnel capacity, but mainly the larger LSPs were able to create additional revenue streams through, e.g. the acquisition of airplanes to provide extra transport capacity for PPE and medical equipment requested by governments.

From a personnel perspective, redundancies could be avoided by using the so-called "short-time work," a subsidized temporary reduction of working hours for employees, which helped to bring the organization quickly up to speed when the recovery phase started. It was also observed that the larger LSPs were quicker to implement digital services, but that digitalization still represents a challenge for the LSPs legacy systems. These findings provided insights into to dynamics behind the Covid-19 reactions and attempts to answer the so far unresolved question how LSPs managed to keep the supply chains resilient and what actions have been taken to maintain operations and uphold financial stability. As such, the paper contributes to the body of knowledge in four ways: First, the study contributes to a better understanding about the impact of Covid-19 on supply chain from a LSP perspective, which has been limited so far. Second, the paper presents and discusses the immediate actions of the mainly operational decisions taken by LSPs, thereby providing an overview about the implications on the LSPs and supply chains. Second, our study provides insight into how LSPs have managed the downsides of the 
pandemic as well as found innovative ways to overcome operational and financial challenges, thereby not only categorizing the LSPs' reactions but also providing an overview about the "lessons learned" from a managerial perspective. Third, by recalibrating the concept of supply chain resilience to LSP resilience, we extend current LSP and supply chain literature with a framework that is better suited to describe the immediate reactions and actions of LSPs during an external shock of high-impact and low-probability.

The findings, however, need to be viewed in the light of their limitations. Although we are confident that our interpretive approach has produced interesting and valid results in the context of COVID-19, we are cautious to generalize our findings. The sample of four LSPs is not only small, but we restricted our research to one country. Thus, the generalization of the results is neither wanted, nor desired, i.e. this study provides a snapshot of the COVID-19 situation in Austria and its implications on LSPs, thereby providing context-specific findings. We invite future researcher to go beyond one country to highlight geographical and contextual similarities and differences. Moreover, although we have developed a specific LSP resilience framework with two key characteristics, other theoretical perspectives such as supply chain security or supply chain vulnerability may be better suited to investigate the reactions from LSPs. And although our LSP resilience framework has helped us to classify and understand the (re) actions of LSPs, future research may elaborate and examine on the similarities and differences to the concept of supply chain resilience and further develop our framework.

We can conclude that research investigating the implications caused by the COVID-19 pandemic from a LSP perspective seems to be still in its infancy. By examining the reactions and actions taken by LSPs, we have taken a first step towards a better understanding of the supply chain resilience through LSPs. We hope that both the findings and the framework presented in this research will spark discussions and projects in the LSP sphere.

\section{References}

Arnould, E.J. and Wallendorf, M. (1994), "Market-oriented ethnography: interpretation building”, fournal of Marketing Research, Vol. 31 No. 4, pp. 484-504.

BMOE (2020), "Auswirkungen der Corona-Krise auf einkauf, versorgung, preise und mehr", Vienna, AT, available at: https://marketingclub.at/assets/BMOE-Blitzumfrage-Corona. pdf

Brenner, M.E. (2006), "Interviewing in educational research", Handbook of Complementary Methods in Education Research, American Educational Research Association, Washington, DC, pp. 357-370.

Busse, C. and Wallenburg, C.M. (2011), "Innovation management of logistics service providers", International Fournal of Physical Distribution E Logistics Management, Vol. 41 No. 2, pp. 187-218.

Cachon, G.P. and Fisher, M. (2000), "Supply chain inventory management and the value of shared information", Management Science, Vol. 46 No. 8, pp. 1032-1048.
Chen, Y.M., Goan, M.-J. and Huang, P.-N. (2011), "Selection process in logistics outsourcing - a view from third party logistics provider", Production Planning E Control, Vol. 22 No. 3, pp. 308-324.

Choi, T.-M. (2020), "Innovative "bring-service-near-yourhome operations under corona-virus (COVID-19/SARSCoV-2) outbreak: can logistics become the messiah?", Transportation Research Part E: Logistics and Transportation Review, Vol. 140, p. 101961.

Christopher, M. (2011), Logistics E Supply Chain Management, Pearson Education, Harlow.

Christopher, M. and Peck, H. (2004), "Building the resilient supply chain", The International fournal of Logistics Management, Vol. 15 No. 2, pp. 1-13.

Cichosz, M., Wallenburg, C.M. and Knemeyer, A.M. (2020), "Digital transformation at logistics service providers: barriers, success factors and leading practices", The International Fournal of Logistics Management, Vol. 31 No. 2.

Coutu, D.L. (2002), "How resilience works", Harvard Business Review, Vol. 80 No. 5, pp. 46-56.

Darby, J.L., Fugate, B.S. and Murray, J.B. (2019), "Interpretive research: a complementary approach to seeking knowledge in supply chain management", The International Fournal of Logistics Management, Vol. 30 No. 2, pp. 395-413.

DB Schenker (2020), "Covid-19 pandemic hits deutsche bahn", available at: www.dbschenker.com/global/about/ press/covid-19-pandemic-hits-db-645108

Deming, W.E. (1990), Sample Design in Business Research, John Wiley \& Sons.

Denzin, N. (1984), "Toward a phenomenology of domestic, family violence", American fournal of Sociology, Vol. 90 No. 3, pp. 483-513.

Dobrovnik, M., Herold, D., Fürst, E. and Kummer, S. (2018), "Blockchain for and in logistics: what to adopt and where to start", Logistics, Vol. 2 No. 3, p. 18, doi: 10.3390/ logistics2030018.

DVZ (2020), "China-Shuttle: DB schenker kooperiert mit icelandair", Deutsche Verkehrszeitung, available at: www. dvz.de/rubriken/land/detail/news/china-shuttle-db-schenkerkooperiert-mit-icelandair.html

Eurofound (2020), "Austria: working time flexibility", available at: www.eurofound.europa.eu/observatories/emcc/ erm/legislation/austria-working-time-flexibility

Fournier, S. (1998), "Consumers and their brands: developing relationship theory in consumer research", fournal of Consumer Research, Vol. 24 No. 4, pp. 343-373.

Fruth, M. and Teuteberg, F. (2017), "Digitization in maritime logistics - what is there and what is missing?", Cogent Business E Management, Vol. 4 No. 1, p. 1411066.

Garay-Rondero, C.L., Martinez-Flores, J.L., Smith, N.R., Morales, S.O.C. and Aldrette-Malacara, A. (2019), "Digital supply chain model in industry 4.0", fournal of Manufacturing Technology Management, Vol. 31 No. 5.

Gartner (2019), “Gartner says $85 \%$ of logistics leaders expect their outsourcing budget to increase in 2020", available at: www.gartner.com/en/newsroom/press-releases/2019-12-12gartner-says-85-of-logistics-leaders-expect-their-ou

Geertz, C. (1973), The Interpretation of Cultures, Basic Books, New York, NY. 
Gkanatsas, E. and Krikke, H. (2020), “Towards a pro-silience framework: a literature review on quantitative modelling of resilient 3PL supply chain network designs", Sustainability, Vol. 12 No. 10, p. 4323.

Golan, M.S., Jernegan, L.H. and Linkov, I. (2020), Trends and Applications of Resilience Analytics in Supply Chain Modeling: systematic Literature Review in the Context of the COVID-19 Pandemic, Environment Systems \& Decisions.

Gölgeci, I. and Ponomarov, S.Y. (2015), "How does firm innovativeness enable supply chain resilience? The moderating role of supply uncertainty and interdependence", Technology Analysis \& Strategic Management, Vol. 27 No. 3, pp. 267-282.

Grawe, S.J. (2009), "Logistics innovation: a literature-based conceptual framework", The International fournal of Logistics Management, Vol. 20 No. 3, pp. 360-377.

Grimson, J.A. and Pyke, D.F. (2007), "Sales and operations planning: an exploratory study and framework", The International fournal of Logistics Management, Vol. 18 No. 3, pp. 322-346.

Gunasekaran, A., Papadopoulos, T., Dubey, R., Wamba, S.F., Childe, S.J., Hazen, B. and Akter, S. (2017), "Big data and predictive analytics for supply chain and organizational performance", Fournal of Business Research, Vol. 70, pp. 308-317.

Hager, J. (2020), "Arbeitsmarkt: 1,3 millionen in österreich in kurzarbeit, 517.221 ohne job”, Kurier, available at: https:// kurier.at/politik/inland/live-die-aktuellen-zahlen-zu-arbeitslos igkeit-und-kurzarbeit/400928603

Herold, D.M., Ćwiklicki, M., Pilch, K. and Mikl, J. (2021), "The emergence and adoption of digitalization in the logistics and supply chain industry: an institutional perspective", Fournal of Enterprise Information Management.

Holmström, J. and Partanen, J. (2014), "Digital manufacturing-driven transformations of service supply chains for complex products", Supply Chain Management: An International fournal, Vol. 19 No. 4, pp. 421-430.

Horton, W. (2020), "These airlines will next remove seats to carry cargo and medical supplies on passenger aircraft turned into freighters", Forbes, available at: www.forbes.com/sites/ willhorton1/2020/04/13/these-airlines-will-next-remove-seatsto-carry-cargo-and-medical-supplies-on-passenger-aircraft-turn ed-into-freighters/\#40506f860938

Hosseini, S., Ivanov, D. and Dolgui, A. (2019), "Review of quantitative methods for supply chain resilience analysis", Transportation Research Part E: Logistics and Transportation Review, Vol. 125, pp. 285-307.

Hribernik, M., Zero, K., Kummer, S. and Herold, D.M. (2020), "City logistics: towards a blockchain decision framework for collaborative parcel deliveries in micro-hubs", Transportation Research Interdisciplinary Perspectives, Vol. 8, pp. 100274.

Hudson, L.A. and Ozanne, J.L. (1988), “Alternative ways of seeking knowledge in consumer research", Fournal of Consumer Research, Vol. 14 No. 4, pp. 508-521.

ICAO (2020), "Effects of novel coronavirus (COVID-19) on civil aviation: economic impact analysis", Montreal, CA, available at: https:/www.icao.int/sustainability/Documents/ COVID-19/ICAO_Coronavirus_Econ_Impact.pdf
Infosys (2019), "2019 Third party logistics study - the state of logistics outsourcing", available at: www.kornferry.com/ content/dam/kornferry/docs/article-migration/2019-3PL-Study. pdf

Ivanov, D. (2020a), "Predicting the impacts of epidemic outbreaks on global supply chains: a simulation-based analysis on the coronavirus outbreak (COVID-19/SARSCoV-2) case", Transportation Research Part E: Logistics and Transportation Review, Vol. 136, p. 101922.

Ivanov, D. (2020b), "Viable supply chain model: integrating agility, resilience and sustainability perspectives - lessons from and thinking beyond the COVID-19 pandemic", Annals of Operations Research.

Ivanov, D. and Das, A. (2020), "Coronavirus (COVID-19/ SARS-CoV-2) and supply chain resilience: a research note", International Fournal of Integrated Supply Management, Vol. 13 No. 1, pp. 90-102.

Ivanov, D. and Dolgui, A. (2020a), "A digital supply chain twin for managing the disruption risks and resilience in the era of industry 4.0", Production Planning E Control, pp. 1-14.

Ivanov, D. and Dolgui, A. (2020b), "Viability of intertwined supply networks: extending the supply chain resilience angles towards survivability: a position paper motivated by COVID19 outbreak", International Fournal of Production Research, Vol. 58 No. 10, pp. 2904-2915.

Ivanov, D., Sokolov, B. and Kaeschel, J. (2010), "A multistructural framework for adaptive supply chain planning and operations control with structure dynamics considerations", European Fournal of Operational Research, Vol. 200 No. 2, pp. 409-420.

Kaipia, R., Holmström, J., Småros, J. and Rajala, R. (2017), "Information sharing for sales and operations planning: contextualized solutions and mechanisms", fournal of Operations Management, Vol. 52 No. 1, pp. 15-29.

Kim, Y., Chen, Y.-S. and Linderman, K. (2015), "Supply network disruption and resilience: a network structural perspective", Fournal of Operations Management, Vol. 33-34 No. 1, pp. 43-59.

König, A. and Spinler, S. (2016), "The effect of logistics outsourcing on the supply chain vulnerability of shippers", The International fournal of Logistics Management, Vol. 27 No. 1, pp. 122-141.

Kramer, A. and Kramer, K.Z. (2020), "The potential impact of the COVID-19 pandemic on occupational status, work from home, and occupational mobility", Fournal of Vocational Behavior, Vol. 119, p. 103442.

Kummer, S., Herold, D.M., Dobrovnik, M., Mikl, J. and Schäfer, N. (2020), "A systematic review of blockchain literature in logistics and supply chain management: identifying research questions and future directions", Future Internet, Vol. 12 No. 3, p. 60.

Lam, J.S.L. and Dai, J. (2015), "Developing supply chain security design of logistics service providers", International fournal of Physical Distribution \& Logistics Management, Vol. 45 No. 7, pp. 674-690.

Lee, C. (2017), “A GA-based optimisation model for big data analytics supporting anticipatory shipping in retail 4.0", International fournal of Production Research, Vol. 55 No. 2, pp. 593-605. 
Lee, H.L. (2002), "Aligning supply chain strategies with product uncertainties", California Management Review, Vol. 44 No. 3, pp. 105-119.

Li, G., Yang, H., Sun, L., Ji, P. and Feng, L. (2010), "The evolutionary complexity of complex adaptive supply networks: a simulation and case study", International Fournal of Production Economics, Vol. 124 No. 2, pp. 310-330.

Liu, C.-L. and Lee, M.-Y. (2018), "Integration, supply chain resilience, and service performance in third-party logistics providers", The International fournal of Logistics Management, Vol. 29 No. 1, pp. 5-21.

Lund, S., Manyika, J., Woetzel, J., Barriball, E., Krishnan, M., Alicke, K., Birshan, M., George, K., Smit, S., Swan, D. and Hutzler, K. (2020), "Risk, resilience, and rebalancing in global value chains", available at: www.mckinsey.com/ $\sim /$ media/McKinsey/Business \%20Functions/Operations/Our $\% 20$ Insights/Risk $\% 20$ resilience $\% 20$ and $\% 20$ rebalancing $\% 20$ in $\% 20$ global $\% 20$ value $\% 20$ chains/Risk-resilience-and-rebala ncing-in-global-value-chains-full-report-vH.pdf

Mayerhofer, P., Bärenthaler-Sieber, S. and Böheim, M. (2020), Oberösterreichs Industrie in Der COVID-19-Krise. Eine Zwischenbilanz, WIFO Studies.

Mikl, J., Herold, D.M., Ćwiklicki, M. and Kummer, S. (2020), "The impact of digital logistics start-ups on incumbent firms: a business model perspective", The International fournal of Logistics Management.

Mikl, J., Herold, D.M., Pilch, K., Ćwiklicki, M. and Kummer, S. (2020), "Understanding disruptive technology transitions in the global logistics industry: the role of ecosystems", Review of International Business and Strategy, Vol. 31 No. 1, pp. 62-79.

Minichiello, V., Aroni, R., Timewell, E. and Alexander, L. (1995), In-Depth Interviewing: Principles, Techniques, Analysis, Pearson Education.

Murray, J.B. (2002), "The politics of consumption: a reinquiry on Thompson and Haytko's (1997)“speaking of fashion”, fournal of Consumer Research, Vol. 29 No. 3, pp. 427-440.

Oliva, R. and Watson, N. (2011), "Cross-functional alignment in supply chain planning: a case study of sales and operations planning", fournal of Operations Management, Vol. 29 No. 5, pp. 434-448.

Panayides, P.M. and So, M. (2005), "Logistics service provider-client relationships", Transportation Research Part E: Logistics and Transportation Review, Vol. 41 No. 3, pp. 179-200.

Parikh, M.A. (2002), "Knowledge acquisition through case study development: a student researcher perspective", Communications of the Association for Information Systems, Vol. 8 No. 1, p. 25.

Paris, C. (2020), “Coronavirus toll on shipping reaches $\$ 350$ million a week", The Wall Street fournal, available at: www. wsj.com/articles/coronavirus-toll-on-shipping-reaches350-million-a-week-11581366671

Pathak, S.D., Dilts, D.M. and Mahadevan, S. (2009), "Investigating population and topological evolution in a complex adaptive supply network", fournal of Supply Chain Management, Vol. 45 No. 3, pp. 54-57.
Paul, S.K. and Chowdhury, P. (2020), “A production recovery plan in manufacturing supply chains for a high-demand item during COVID-19", International fournal of Physical Distribution E Logistics Management, Vol. 51 No. 2.

Pereira, C.R., Christopher, M. and Da Silva, A.L. (2014), "Achieving supply chain resilience: the role of procurement", Supply Chain Management: An International fournal, Vol. 19 Nos 5/6, pp. 626-642.

Pettit, T.J., Croxton, K.L. and Fiksel, J. (2019), "The evolution of resilience in supply chain management: a retrospective on ensuring supply chain resilience", fournal of Business Logistics, Vol. 40 No. 1, pp. 56-65.

Pettit, T.J., Fiksel, J. and Croxton, K.L. (2010), "Ensuring supply chain resilience: development of a conceptual framework", fournal of Business Logistics, Vol. 31 No. 1, pp. 1-21.

Ponis, S.T. and Koronis, E. (2012), "Supply chain resilience? Definition of concept and its formative elements", fournal of Applied Business Research (Fabr), Vol. 28 No. 5, pp. 921-935.

Ponomarov, S.Y. and Holcomb, M.C. (2009), "Understanding the concept of supply chain resilience", The International fournal of Logistics Management, Vol. 20 No. 1, pp. 124-143.

Prasad, P. (2017), Crafting Qualitative Research: Beyond Positivist Traditions, Taylor \& Francis.

Putzger, I. (2020), "Sourcing PPE dominates air capacity and pushes rates, but more lift is on the way", The Loadstar, available at: https://theloadstar.com/sourcing-ppe-dominatesair-capacity-and-pushes-rates-but-more-lift-is-on-the-way/

Queiroz, M.M., Ivanov, D., Dolgui, A. and Wamba, S.F. (2020), "Impacts of epidemic outbreaks on supply chains: mapping a research agenda amid the COVID-19 pandemic through a structured literature review", Annals of Operations Research, pp. 1-38.

Queiroz, M.M., Pereira, S.C.F., Telles, R. and Machado, M. C. (2019), "Industry 4.0 and digital supply chain capabilities", Benchmarking: An International fournal.

Rabinovich, E. and Cheon, S. (2011), "Expanding horizons and deepening understanding via the use of secondary data sources", fournal of Business Logistics, Vol. 32 No. 4, pp. 303-316.

Rangarajan, D., Sharma, A., Paesbrugghe, B. and Boute, R. (2018), "Aligning sales and operations management: an agenda for inquiry", fournal of Personal Selling \& Sales Management, Vol. 38 No. 2, pp. 220-240.

Remko, vH. (2020), "Research opportunities for a more resilient post-COVID-19 supply chain-closing the gap between research findings and industry practice", International fournal of Operations \& Production Management, Vol. 40 No. 4.

Roßmann, B., Canzaniello, A., von der Gracht, H. and Hartmann, E. (2018), "The future and social impact of big data analytics in supply chain management: results from a Delphi study", Technological Forecasting and Social Change, Vol. 130, pp. 135-149.

Rubin, H.J. and Rubin, I.S. (2011), Qualitative Interviewing: The Art of Hearing Data, Sage, Thousand Oaks, CA.

Saberi, S., Kouhizadeh, M., Sarkis, J. and Shen, L. (2019), "Blockchain technology and its relationships to sustainable supply chain management", International 
Fournal of Production Research, Vol. 57 No. 7, pp. 2117-2135.

Schnetzer, M., Tamesberger, D. and Theurl, S. (2020), "Mitigating mass layoffs in the COVID-19 crisis: Austrian short-time work as international role model", Vox CEPR Policy Portal, available at: https://voxeu.org/article/mitigating-masslayoffs-covid-19-crisis-austrian-short-time-model

Scholten, K., Scott, P.S. and Fynes, B. (2014), "Mitigation processes - antecedents for building supply chain resilience", Supply Chain Management: An International fournal, Vol. 19 No. 2, pp. 211-228.

Sharma, M., Luthra, S., Joshi, S. and Kumar, A. (2020), "Developing a framework for enhancing survivability of sustainable supply chains during and post-COVID-19 pandemic", International Fournal of Logistics Research and Applications, pp. 1-21.

Singh, S., Kumar, R., Panchal, R. and Tiwari, M.K. (2020), "Impact of COVID-19 on logistics systems and disruptions in food supply chain", International fournal of Production Research, pp. 1-16.

Småros, J., Lehtonen, J.M., Appelqvist, P. and Holmström, J. (2003), "The impact of increasing demand visibility on production and inventory control efficiency", International Fournal of Physical Distribution $\mathcal{E}$ Logistics Management, Vol. 33 No. 4, pp. 336-354.

Stank, T., Esper, T., Goldsby, T.J., Zinn, W. and Autry, C. (2019), "Toward a digitally dominant paradigm for twentyfirst century supply chain scholarship", International fournal of Physical Distribution \& Logistics Management, Vol. 49 No. 10, pp. 956-971.

Statistik Austria (2020), “Transportaufkommen österreichischer unternehmen im straßengüterverkehr im 2. Quartal 2020 um fast 15\% eingebrochen", [Press release], available at: www.statistik.at/web_de/statistiken/ energie_umwelt_innovation_mobilitaet/verkehr/strasse/gueterve rkehr/124048.html

Svensson, G. (2001), "The impact of outsourcing on inbound logistics flows", The International Fournal of Logistics Management, Vol. 12 No. 1, pp. 21-35.

Swierczek, A. (2019), "Using triple-loop learning to identify adaptive behaviour of resilient supply chain", Transport Economics and Logistics, Vol. 78, pp. 7-17.

The Economist (2018), "The global logistics business is going to be transformed by digitization", The Economist, available at: www.economist.com/briefing/2018/04/26/the-globallogistics-business-is-going-to-be-transformed-by-digitisation

Thompson, C. (1997), "Interpreting consumers: a hermeneutical framework for deriving marketing insights from the texts of consumers' consumption stories", fournal of Marketing Research, Vol. 34 No. 4, pp. 438-455.

Thompson, C., Locander, W. and Pollio, H. (1989), "Putting consumer experience back into consumer research: the philosophy and method of existentialphenomenology", fournal of Consumer Research, Vol. 16 No. 2, pp. 133-146.

Tukamuhabwa, B.R., Stevenson, M., Busby, J. and Zorzini, M. (2015), "Supply chain resilience: definition, review and theoretical foundations for further study", International fournal of Production Research, Vol. 53 No. 18, pp. 5592-5623.

UPS (2020), "UPS releases 2Q 2020 earnings", available at: www.investors.ups.com/news-releases/news-release-details/upsreleases-2q-2020-earnings

Wackett, M. (2020), "Coronavirus may be costing container shipping lines $\$ 350 \mathrm{~m}$ every week", The Loadstar, available at: https://theloadstar.com/coronavirus-may-be-costingcontainer-shipping-lines-350m-every-week/

Waller, M., Williams, B.D. and Tokar, T. (2008), “A review of inventory management research in major logistics journals", The International fournal of Logistics Management, Vol. 21 No. 1, pp. 404-489.

Wilson, G. (2020), "How COVID-19 has transformed the logistics and 3PL industry", Supply Chain, available at: www. supplychaindigital.com/logistics/how-covid-19-has-transformedlogistics-and-3pl-industry

Wimpenny, P. and Gass, J. (2000), "Interviewing in phenomenology and grounded theory: is there a difference?", Fournal of Advanced Nursing, Vol. 31 No. 6, pp. 1485-1492.

Yang, C.-S. (2019), "Maritime shipping digitalization: blockchain-based technology applications, future improvements, and intention to use", Transportation Research Part E: Logistics and Transportation Review, Vol. 131, pp. 108-117.

Yin, R.K. (2014), Case Study Research: Design and Methods, SAGE, Thousand Oaks, CA.

\section{Corresponding author}

David M. Herold can be contacted at: dherold@wu.ac.at 